\title{
Curcumin suppresses MUC5AC production via interfering with the EGFR signaling pathway
}

\author{
LINGLING TANG $^{1 *}$, QINGGE CHEN ${ }^{1 *}$, LI SUN $^{1 *}$, LINYUN ZHU $^{1}$, JINJIN LIU ${ }^{1}$, \\ ZIYU MENG ${ }^{1}$, ZHENHUA NI ${ }^{2}$ and XIONGBIAO WANG ${ }^{1}$ \\ ${ }^{1}$ Department of Respiratory Medicine; ${ }^{2}$ Central Laboratory, Putuo Hospital, \\ Shanghai University of Traditional Chinese Medicine, Shanghai 200062, P.R. China
}

Received March 6, 2017; Accepted March 23, 2018

DOI: $10.3892 /$ ijmm.2018.3609

\begin{abstract}
Excessive mucin production in the airway may contribute to airway inflammatory diseases. Curcumin has been reported to prevent mucin 5AC (MUC5AC) production in human airway epithelial cells; however, the molecular targets of curcumin involved in regulating MUC5AC expression have remained elusive. The present study aimed to elucidate the molecular mechanisms by which curcumin regulates MUC5AC production, utilizing the NCI-H292 human airway epithelial cell line featuring MUC5AC hypersecretion. Curcumin was able to counteract the endothelial growth factor (EGF)-stimulated mRNA and protein expression of MUC5AC. In addition, curcumin treatment prevented EGF-induced phosphorylation of EGF receptor (EGFR) as well as the downstream AKT and signal transducer and activator of transcription 3 (STAT3), while inhibition of PI3K and STAT3 signaling significantly attenuated the expression of MUC5AC that was induced by EGF. Furthermore, EGF-induced increases in the levels of phosphorylated STAT3 in the nuclear fraction were inhibited by curcumin and PI3K inhibitors. In addition, treatment with curcumin significantly decreased MUC5AC and EGFR expression in a time-dependent manner under basal conditions. These results demonstrated that curcumin inhibited MUC5AC protein expression in NCI-H292 cells under basal conditions as well under EGF stimulation. This
\end{abstract}

Correspondence to: Mr. Zhenhua Ni, Central Laboratory, Putuo Hospital, Shanghai University of Traditional Chinese Medicine, 164 Lanxi Road, Shanghai 200062, P.R. China

E-mail: zhenhuani@yeah.net

Dr Xiongbiao Wang, Department of Respiratory Medicine, Putuo Hospital, Shanghai University of Traditional Chinese Medicine, 164 Lanxi Road, Shanghai 200062, P.R. China

E-mail: xiongbiao6@yahoo.com

${ }^{*}$ Contributed equally

Key words: curcumin, endothelial growth factor receptor, mucin $5 \mathrm{AC}$, signal transducer and activator of transcription 3 inhibition was accompanied by decreased activation of the EGFR/AKT/STAT3 pathway and reduced EGFR expression, which indicated that curcumin may have a dual role in interfering with the EGFR signaling pathway and inhibiting mucin expression in human airway epithelial cells.

\section{Introduction}

Asthma is one of the most frequent chronic respiratory diseases worldwide and its prevalence has increased over the last decade (1). This disease is generally characterized by a chronic inflammatory response in all airways, which leads to increased airway mucus-secreting cells and increased mucus secretion, and contributes to the formation of mucus plugs that occlude asthmatic airways, potentially leading to possibly fatal asthma attacks $(2,3)$. Although current pharmacotherapies are effective for most patients, asthma has yet to be controlled in a systematic and satisfactory manner, and no specific treatment is currently available for mucus hypersecretion (4).

Curcumin, a polyphenol, is the major active component of turmeric. Various studies have documented the therapeutic benefits of curcumin in managing various disorders due to its anti-inflammatory, anti-oxidant and anti-viral properties (5-7). Curcumin was previously reported to effectively control the occurrence and development of asthma by reducing inflammation, inhibiting airway remodeling and maintaining structural integrity (8). Furthermore, Heo et al (9) revealed that curcumin suppressed endothelial growth factor (EGF)-induced mucin 5AC (MUC5AC) production in human airway epithelial cells, which indicated that it may be a promising agent for treating mucin overproduction. However, the underlying mechanisms have remained to be elucidated.

MUC5AC expression is induced by various stimuli, including interleukin-13 (IL-13), tumor necrosis factor- $\alpha$, EGF, neutrophil elastase and bacterial products (10-13). These stimuli are principally mediated via the EGF receptor (EGFR) signaling pathway, including the downstream c-Jun-N-terminal kinase, extracellular signal-regulated kinase or AKT, which has been identified as a key effector for mucin production (14-16). According to Heo et al (9), curcumin inhibited MUC5AC protein production that was induced by EGF, indicating that the EGFR-mediated signaling pathway may be a target for curcumin; however, the exact mechanism remains elusive. 
In the present study, the effect of curcumin on MUC5AC expression in NCI-H292 cells was investigated and its role in regulating the EGFR signaling pathway was explored.

\section{Materials and methods}

Cell culture. The NCI-H292 human lung mucoepidermoid carcinoma cell line (The Cell Bank of Type Culture Collection of Chinese Academy of Sciences, Shanghai, China) was maintained in RPMI-1640 medium supplemented with $10 \%$ fetal bovine serum, penicillin and streptomycin (all from Thermo Fisher Scientific, Inc., Waltham, MA, USA). Cells were treated with curcumin $\left(20 \mu \mathrm{M}\right.$ at $37^{\circ} \mathrm{C}$ for $0,1,3,24$ and $48 \mathrm{~h}$ or 10 and $30 \mathrm{~min} ; 10 \mu \mathrm{M}$ at $37^{\circ} \mathrm{C}$ for $48 \mathrm{~h}$; Selleck Chemicals, Houston, TX, USA), EGF (50 ng/ml at $37^{\circ} \mathrm{C}$ for $0,3,24$ and $48 \mathrm{~h}$, or 10 and 30 min; PeproTech, Inc., Rocky Hill, NJ, USA), PI3K inhibitor LY294002 $\left(25 \mu \mathrm{M}\right.$ at $37^{\circ} \mathrm{C}$ for $30 \mathrm{~min}$ or $\left.48 \mathrm{~h}\right)$ and a STAT3 inhibitor STATTIC $\left(10 \mu \mathrm{M}\right.$ at $37^{\circ} \mathrm{C}$ for $48 \mathrm{~h}$ ) (both from Selleck Chemicals).

Reverse transcription-quantitative polymerase chain reaction $(R T-q P C R)$. Total RNA was isolated using TRIzol reagent (Thermo Fisher Scientific, Inc.) and first-strand complementary DNAs were prepared using a random hexamer primer according to the instructions included in the First-Strand Synthesis kit (cat. no. 04897030001; Roche Diagnostics, Basel, Switzerland). PCR was performed using specific forward and reverse primers (MUC5AC forward, 5'-GCTTCCTGCTCC GAGATGT-3' and reverse, 5'-AAGACGCAGCCCTCATAG AA-3'; $\beta$-actin forward, 5'-CCAACCGCGAGAAGATGA-3' and reverse, 5'-CCAGAGGCGTACAGGGATAG-3'; EGFR forward, 5'-AGGCACGAGTAACAAGCTCAC-3' and reverse, 5'-ATGAGGACATAACCAGCCACC-3'). Real-time PCR was performed using Universal Master Mix (Roche Diagnostics) on an ABI Real-Time PCR system (Applied Biosystems; Thermo Fisher Scientific, Inc.). The conditions for the amplifications were as follows: $10 \mathrm{~min}$ at $95^{\circ} \mathrm{C}$, followed by 45 two-step cycles at $95^{\circ} \mathrm{C}$ for $15 \mathrm{sec}$ and $60^{\circ} \mathrm{C}$ for $1 \mathrm{~min}$. The relative expression levels of the MUC5AC and EGFR were normalized against $\beta$-actin. PCR results were quantified by using the $2^{-\Delta \Delta C q}$ method (17).

Western blot analysis. The cells were washed once in PBS and dissolved in cell lysis reagents (Cell Signaling Technology, Inc., Danvers, MA, USA). The lysis buffer constituted $20 \mathrm{mM}$ Tris- $\mathrm{HCl}$ (pH 7.5), $150 \mathrm{mM} \mathrm{NaCl}, 1 \mathrm{mM} \mathrm{Na}{ }_{2}$ EDTA, $1 \mathrm{mM}$ EGTA, 1\% Triton, $2.5 \mathrm{mM}$ sodium pyrophosphate, $1 \mathrm{mM}$ $\beta$-glycerophosphate, $1 \mathrm{mM} \mathrm{Na}_{3} \mathrm{VO}_{4}$ and $1 \mu \mathrm{g} / \mathrm{ml}$ leupeptin. The supernatants were harvested after centrifugation at $13,400 \mathrm{x} \mathrm{g}$ for $15 \mathrm{~min}$ in $4^{\circ} \mathrm{C}$. The protein concentrations were determined by the bicinchoninic acid assay (Beyotime Institute of Biotechnology, Jiangsu, China). The total isolated protein was separated by $6 \%$ SDS-PAGE for MUC5AC detection as described by Ruchaud-Sparagano et al (18) or $10 \%$ SDS-PAGE for the other target proteins, followed by transfer to a polyvinylidene difluoride (PVDF) membrane (EMD Millipore, Billerica, MA, USA). The PVDF membranes were blocked with 5\% bovine serum albumin (Sangon Biotech, Co., Ltd., Shanghai, China), washed twice with Tris-buffered saline containing Tween-20 (TBST), and then incubated with the antibodies separately overnight at $4^{\circ} \mathrm{C}$. The antibodies to $\beta$-actin (1:1,000; cat. no. 4967), phosphorylated (p)-EGFR (Tyr1045 or Tyr1068) (1:1,000; cat. nos. 2237 or 3777, respectively), EGFR (1:1,000; cat. no. 4267), AKT (1:1,000; cat. no. 4691), p-AKT (Ser473) (1:1,000; cat. no. 4060), STAT3 (1:1,000; cat. no. 4904) and p-STAT3 (1:1,000; cat. no. 9145) were all purchased from Cell Signaling Technology, Inc. and the antibodies to MUC5AC (1:1,000; cat. no. sc-21701), were obtained from Santa Cruz Biotechnology Inc. (Dallas, TX, USA). The membranes were then washed with TBST three times, followed by incubation with horseradish peroxidase-conjugated anti-rabbit immunoglobulin G (1:1,000; cat. no. 7074S; Cell Signaling Technology, Inc.) as the secondary antibody for $2 \mathrm{~h}$ at room temperature. Finally, immunoreactive bands were detected by enhanced chemiluminescence reagent (Bio-Rad Laboratories, Inc., Hercules, CA, USA) by luminometer (Shanghai PeiQing Science \& Technology, Co., Ltd., Shanghai, China). Protein levels were quantified using ImageJ version 1.51 software (National Institutes of Health, Bethesda, MD, USA).

Nuclear protein extraction. NCI-H292 cells were harvested and nuclear protein fractions were isolated using a NE-PER Nuclear and Cytoplasmic Extraction Kit (Thermo Fisher Scientific, Inc.) according to the manufacturer's instructions.

Immunocytochemistry. Cells were seeded in 96-well plates at a density of $1 \times 10^{4}$ cells/well and treated with curcumin, EGF, STATTIC, or LY294002. Cells were fixed on slides using $4 \%$ paraformaldehyde for $2 \mathrm{~min}$ at room temperature. The cells were permeabilized three times for $5 \mathrm{~min}$ with $0.1 \%$ Triton X-100 in PBS and blocked with blocking buffer (10\% normal goat serum purchased from Hangzhou Sijiqing Biological Engineering Materials Co., Ltd., Hangzhou, China, $0.1 \%$ Triton X-100) for $30 \mathrm{~min}$ at room temperature. After blocking, the cells were washed with PBS and incubated for $2 \mathrm{~h}$ at $37^{\circ} \mathrm{C}$ with biotin-labeled anti-human MUC5AC (1:200; cat. no. Ab79082; Abcam, Cambridge, UK). Subsequently, the cells were washed three times with PBS, incubated for 30 min with horseradish peroxidase-streptavidin (1:1,000; cat. no. 43-8323; Thermo Fisher Scientific, Inc.), and washed with PBS for another three times. The sections were visualized using diaminobenzidine solution (Fuzhou Maixin Biotech Co., Ltd., Fuzhou, China) for $1 \mathrm{~min}$ at room temperature.

Statistical analysis. SPSS version 21.0 software (IBM Corp., Armonk, NY, USA) was used for all data analyses. Values are expressed as the mean \pm standard deviation. Statistical significance was determined by one-way analysis of variance followed by the Dunnett's method or the least-significant differences test. $\mathrm{P}<0.05$ was considered to indicate a statistically significant difference.

\section{Results}

Effect of EGF on MUC5AC expression. NCI-H292 cells were used to evaluate the effect of EGF on MUC5AC expression in airway cells. NCI-H292 cells were used as an in vitro model for mucin production, as this cell line shares key components of mucin signaling pathways (19). EGF-stimulated H292 cells displayed upregulated expression of MUC5AC mRNA 
A

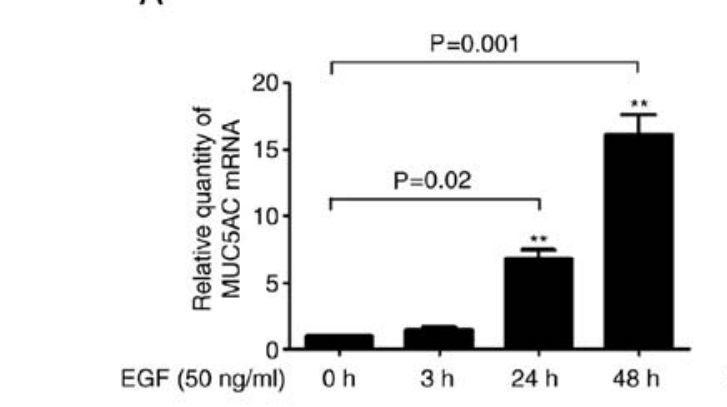

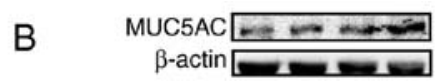

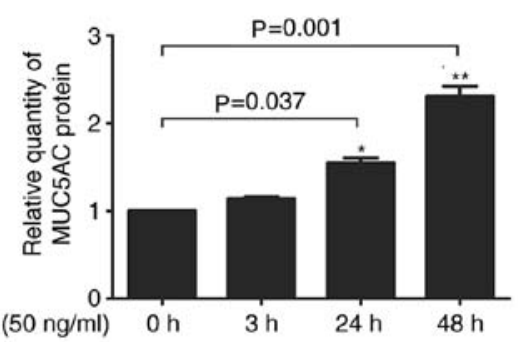

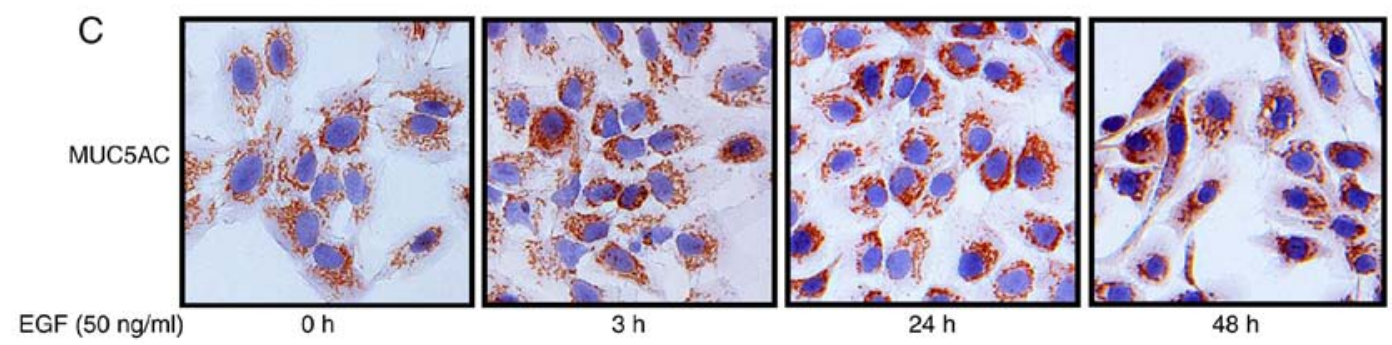

Figure 1. EGF stimulates MUC5AC expression in H292 cells. H292 cells were treated with EGF $(50 \mathrm{ng} / \mathrm{ml})$ or vehicle (PBS with $0.1 \%$ bovine serum albumin) for different exposure times (3, 24 and $48 \mathrm{~h}$ ). (A) The expression of MUC5AC mRNA was determined via quantitative polymerase chain reaction, and (B and C) MUC5AC protein was assessed by western blot and immunocytochemical analysis (magnification, $\mathrm{x} 200$ ), respectively. Positive staining of MUC5AC was stained with a diaminobenzidine solution and indicated as brown color. The nuclei were stained with hematoxylin and indicated as blue color. Results were obtained from 3 separate experiments. Values are expressed as the mean \pm standard deviation. ${ }^{*} \mathrm{P}<0.05,{ }^{* *} \mathrm{P}<0.01$ vs. control group. EGF, endothelial growth factor; MUC5AC, mucin 5AC.

in a time-dependent manner (Fig. 1A), and EGF treatment significantly increased MUC5AC protein expression as detected by western blot analysis and immunohistochemistry (Fig. 1B and C), which is consistent with the upregulation at the mRNA level.

Curcumin inhibits EGF-induced expression of MUC5AC. EGF treatment slightly increased MUC5AC expression after $3 \mathrm{~h}$, but the expression was markedly upregulated at 24 and $48 \mathrm{~h}$ (Fig. 1). NCI-H292 cells were then treated with curcumin (10 and $20 \mu \mathrm{M})$ plus EGF $(50 \mathrm{ng} / \mathrm{ml})$ for $48 \mathrm{~h}$. Curcumin treatment markedly decreased MUC5AC mRNA expression in a dose-dependent manner in EGF-stimulated H292 cells (Fig. 2A). In addition, MUC5AC protein expression was greatly reduced in the curcumin-treated, EGF-stimulated H292 cells compared with that in the curcumin-untreated, EGF-stimulated H292 cells, which is consistent with the downregulation of MUC5AC mRNA observed (Fig. 2B). Decreases of EGF-induced MUC5AC protein expression by curcumin were also confirmed by immunocytochemistry (Fig. 2C).

Curcumin inhibits EGF-induced activation of EGFR phosphorylation. In order to explore the effect of curcumin on the EGFR signaling pathway, activation of EGFR in NCI-H292 cells was investigated after treatment with EGF and curcumin. The results indicated that curcumin treatment inhibited EGFR phosphorylation at Tyr1045 and Tyr1068 in EGF-stimulated cells (Fig. 3).

The AKT-STAT3 pathway is responsible for the inhibitory effect of curcumin on EGF-induced MUC5AC expression. The AKT-STAT3 pathway is a downstream target of EGFR signaling (20); thus, the phosphorylation status of AKT and
STAT3 was determined in NCI-H292 cells treated with EGF and curcumin. EGF-stimulated NCI-H292 cells displayed elevated levels of p-AKT-Ser473 and p-STAT3; however, simultaneous curcumin treatment reduced this phosphorylation (Fig. 4A and B). In addition, EGF-induced increases in STAT3 phosphorylation in the nuclear fraction were inhibited by curcumin and an PI3K inhibitor (Fig. 4C and D). In addition, NCI-H292 cells treated with an PI3K inhibitor (LY294002) and a STAT3 inhibitor (STATTIC) exhibited a significant reduction in MUC5AC expression compared with that in EGF-stimulated cells (Fig. 5). These results indicated that curcumin attenuated MUC5AC expression by inhibiting the PI3K/AKT/STAT3 signaling pathway.

Curcumin inhibits the expression of MUC5AC and EGFR under basal conditions. The effect of curcumin on MUC5AC expression under basal conditions was next investigated. Treatment with curcumin significantly decreased MUC5AC expression in a time-dependent manner at the protein level (Fig. 6A and B). In addition, the expression of EGFR was also decreased after curcumin treatment (Fig. 6C and D). These results suggested that downregulation of EGFR expression was involved in the inhibitory effects of curcumin.

\section{Discussion}

Mucus hypersecretion is an independent risk factor for asthma that has an important impact on its occurrence, development and prognosis (21). It has been indicated that curcumin, a naturally occurring dietary polyphenol, has beneficial effects against the acute allergic asthma response (22). However, the potential role of curcumin in reducing mucus hypersecretion in asthma has remained to be fully investigated. The 


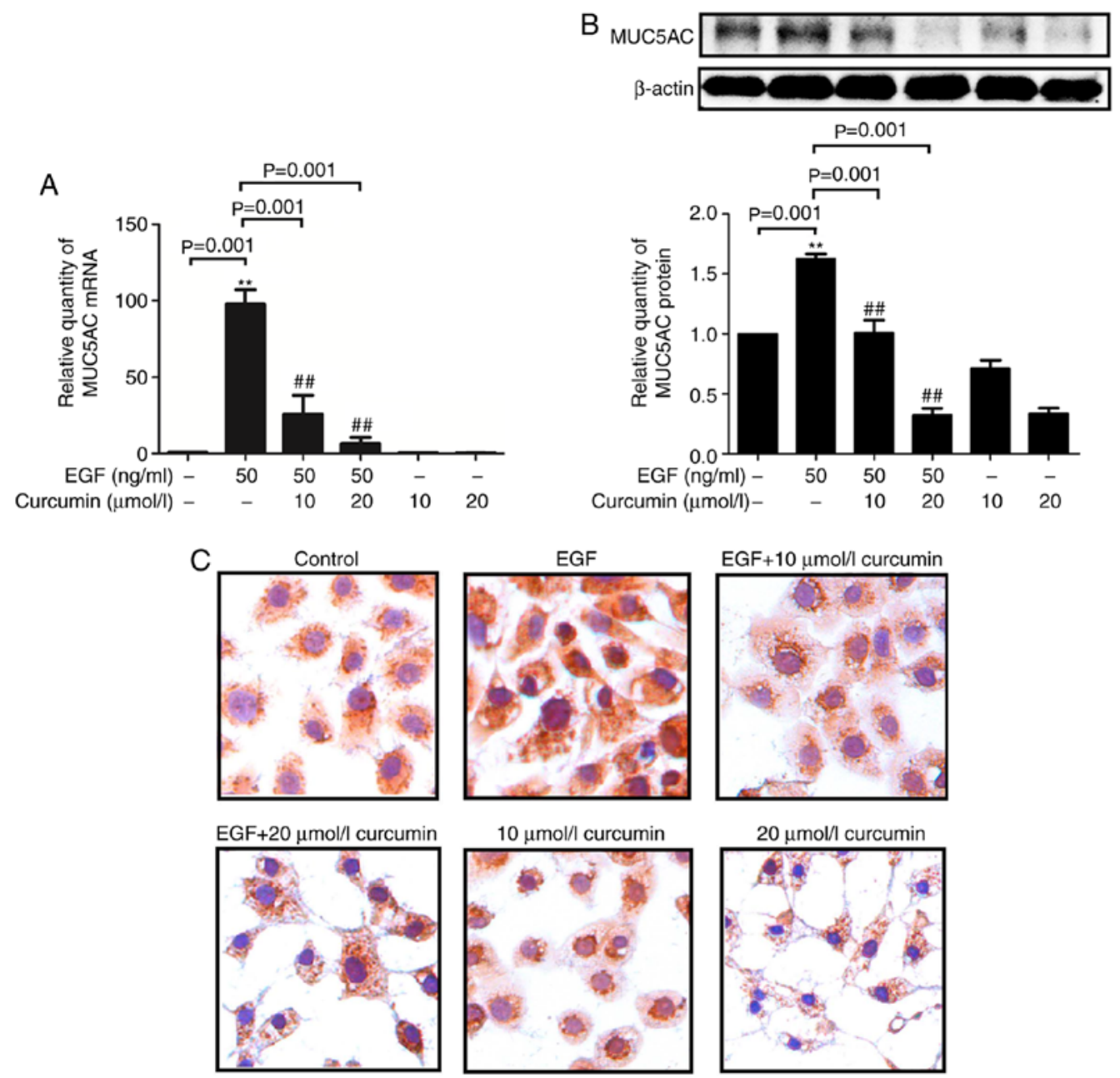

Figure 2. Curcumin reduces MUC5AC expression in EGF-stimulated H292 cells. H292 cells were treated with EGF (50 ng/ml) and curcumin (10 and $20 \mu \mathrm{M})$ or vehicle ( $0.1 \%$ dimethylsulfoxide in PBS with $0.1 \%$ bovine serum albumin) for $48 \mathrm{~h}$. The expression of (A) MUC5AC mRNA and (B and C) protein was determined via reverse transcription-quantitative polymerase chain reaction, western blot and immunocytochemical analysis (magnification, x200), respectively. Results were obtained from 3 separate experiments. Values are expressed as the mean \pm standard deviation. ${ }^{* *} \mathrm{P}<0.01$ vs. control group; ${ }^{\# \#} \mathrm{P}<0.01 \mathrm{vs}$. EGF-induced model group. EGF, endothelial growth factor; MUC5AC, mucin 5AC.
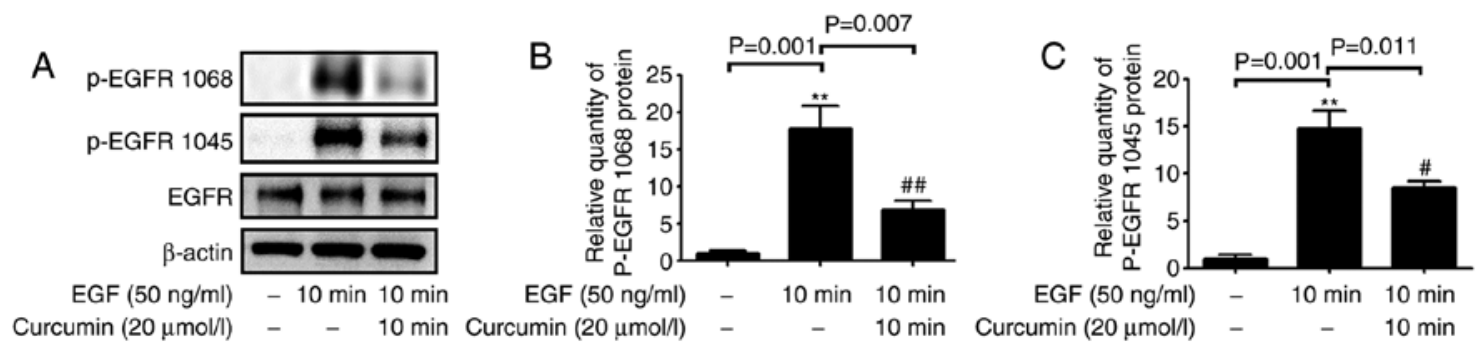

Figure 3. Effect of curcumin on EGF-induced EGFR phosphorylation. H292 cells were treated with curcumin $(20 \mu \mathrm{M})$ and EGF (50 ng/ml) or vehicle ( $0.1 \%$ dimethylsulfoxide in PBS with $0.1 \%$ bovine serum albumin) for $10 \mathrm{~min}$, and EGFR phosphorylation on Tyr1068 and Tyr1045 was determined by western blot analysis. (A) Representative western blot image and (B and C) quantification of EGFR phosphorylation on (B) Tyr1068 and (C) Tyr1045 relative to total EGFR. Results were obtained from 3 separate experiments. Values are expressed as the mean \pm standard deviation. ${ }^{* *} \mathrm{P}<0.01 \mathrm{vs}$. control group; ${ }^{*} \mathrm{P}<0.05$, ${ }^{\#} \mathrm{P}<0.01$ vs. EGF-induced model group. p-EGFR, phosphorylated endothelial growth factor receptor.

present study investigated the possible mechanism of action of curcumin in reducing airway mucus hypersecretion. Assessment of changes in p-EGFR, p-AKT, p-STAT3 levels and EGFR expression under basal and EGF-stimulated conditions revealed that curcumin displays inhibitory effects on MUC5AC expression under such conditions by interfering with EGFR signaling in $\mathrm{H} 292$ cells.
Activation of the EGFR signaling pathway has been reported to have a critical role in mucin regulation (23-25). EGF binds to the extracellular domain of EGFR, which results in receptor dimerization and phosphorylation of the intracellular domains. Activated EGFR activates downstream molecules, including AKT, which in turn activate MUC5AC gene expression. Therefore, increased EGFR kinase activity 

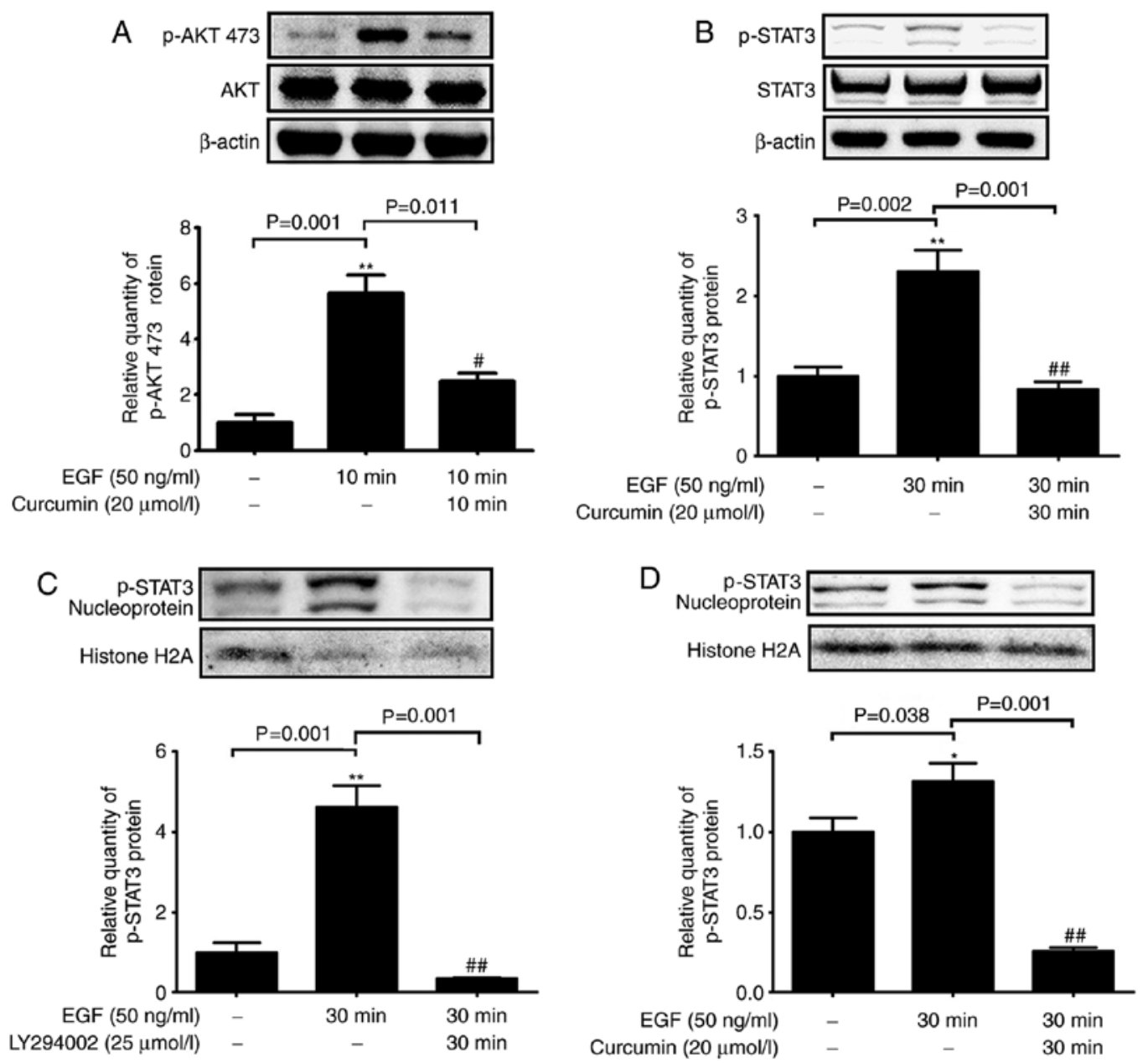

Figure 4. Effect of curcumin on AKT and STAT3 phosphorylation. H292 cells were treated with curcumin (20 $\mu \mathrm{M})$ and EGF (50 ng/ml) or vehicle $(0.1 \%$ dimethylsulfoxide in PBS with $0.1 \%$ bovine serum albumin) for different exposure times (10 or $30 \mathrm{~min}$ ). The phosphorylation of (A) AKT-Ser473 and (B) STAT3 was determined by western blot analysis. (C and D) H292 cells were treated with LY294002 $(25 \mu \mathrm{M})$ or curcumin $(20 \mu \mathrm{M})$ and EGF $(50 \mathrm{ng} / \mathrm{ml})$ for $30 \mathrm{~min}$. Nuclear p-STAT3 was detected by western blot analysis. Results were obtained from 3 separate experiments. Values are expressed as the mean \pm standard deviation. ${ }^{*} \mathrm{P}<0.05,{ }^{* * *} \mathrm{P}<0.01$ vs. control group; ${ }^{*} \mathrm{P}<0.05,{ }^{\# \#} \mathrm{P}<0.01$ vs. EGF-induced model group. EGF, endothelial growth factor; p-STAT3, phosphorylated signal transducer and activator of transcription 3 .

is critical for constitutive mucin production $(26,27)$. In the present study, the AKT/STAT3 pathway was assessed as a downstream target of EGFR signaling, and was identified to be responsible for the inhibitory effect of curcumin on EGF-induced MUC5AC expression. More importantly, EGF treatment of NCI-H292 cells increased MUC5AC, p-AKT and p-STAT3 levels, whereas co-treatment with the PI3K inhibitor LY294002 or curcumin reduced MUC5AC, p-AKT and p-STAT3 levels. These results implied that EGF induced crosstalk between the EGFR/STAT3 and EGFR/AKT pathways in regulating MUC5AC expression, whereas curcumin may interfere with this signaling cascade. However further loss-and gain-of function experiments should be conducted to fully demonstrate this mechanism.

In the present study, curcumin significantly inhibited EGFR phosphorylation in NCI-H292 cells. Using biomimetic membrane models, Starok et al (28) observed that curcumin is inserted into the lipid bilayer and may affect receptor dimerization, which in turn affects EGFR activation. However, additional study is required to confirm this mechanism. In the present study, curcumin altered total EGFR expression in NCI-H292 cells, which indicated that inhibition of EGFR expression partially reflected the molecular mechanism by which curcumin regulates EGFR phosphorylation. The regulatory mechanisms of EGFR expression by curcumin have been investigated by several groups $(29,30)$. In the present study, changes in EGFR phosphorylation occurred earlier than the decrease in EGFR mRNA levels when the cells were treated with curcumin, suggesting that curcumin regulates EGFR at the transcriptional and post-translational levels. This represents a novel mechanism of action of curcumin in human bronchial epithelial cells, which may be applied for treating mucin overproduction.

Curcumin has also been reported to decrease IL-1 $\beta$-induced MUC5AC expression, which suggests that curcumin may interfere with other signaling pathways in addition to EGFR/AKT signaling (31). Furthermore, Song et al (32) demonstrated that curcumin also decreases the transcription of MUC2, another important human mucin gene. In a mouse model, curcumin was administered through the nasal route, suggesting a novel and efficient delivery method (33). Thus, curcumin therapy may be a practical treatment for mucus hypersecretion. However, evidence for the use of curcumin in asthma remains sparse and has mostly been obtained using either in vitro or 


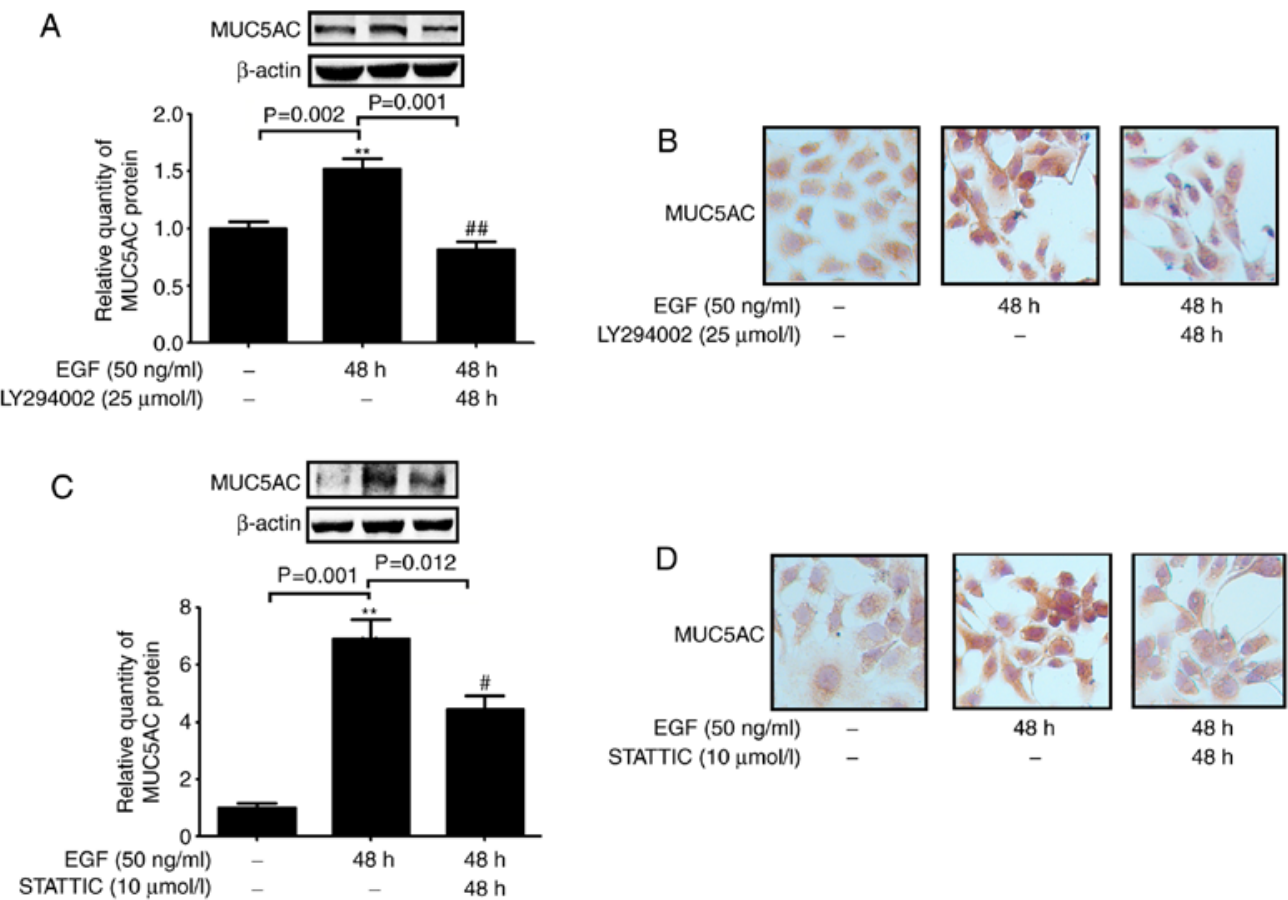

Figure 5. Effect of an PI3K inhibitor (LY294002) and a signal transducer and activator of transcription 3 inhibitor (STATTIC) on EGF-induced MUC5AC expression. H292 cells were treated with LY294002 (25 $\mu \mathrm{M})$, STATTIC $(10 \mu \mathrm{M})$ and EGF $(50 \mathrm{ng} / \mathrm{ml})$ or vehicle $(0.1 \%$ dimethylsulfoxide in PBS with $0.1 \%$ bovine serum albumin) for $48 \mathrm{~h}$. The expression of MUC5AC protein was determined via (A and C) western blot and (B and D) immunocytochemistry (magnification, $\mathrm{x} 200$ ). Results were obtained from 3 separate experiments. Values are expressed as the mean \pm standard deviation. ${ }^{* * *} \mathrm{P}<0.01 \mathrm{vs.}$ control group; ${ }^{\#} \mathrm{P}<0.05,{ }^{\# \#} \mathrm{P}<0.01$ vs. EGF-induced model group. EGF, endothelial growth factor; MUC5AC, mucin 5AC.

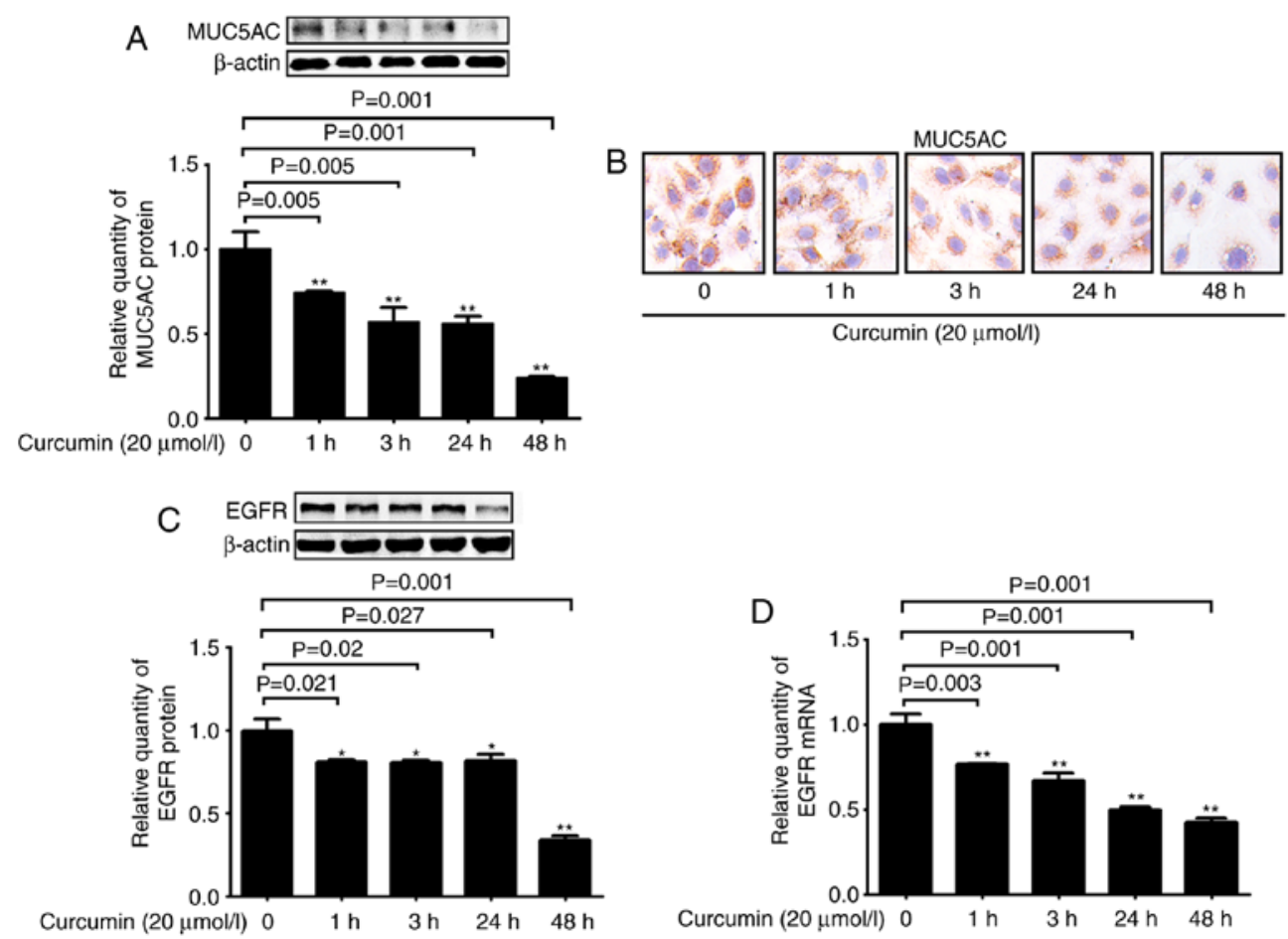

Figure 6. Effect of curcumin on EGFR expression under basal conditions. H292 cells were treated with curcumin $(20 \mu \mathrm{M})$ or vehicle (dimethylsulfoxide, $0.1 \%)$ for different exposure times and subsequently harvested for analysis. MUC5AC protein expression was determined via (A) western blot analysis and (B) immunocytochemistry (magnification, $x 200$ ). EGFR mRNA and protein was determined via (C) western blot and (D) reverse transcription-quantitative polymerase chain reaction. Results were obtained from 3 separate experiments. Values are expressed as the mean \pm standard deviation. ${ }^{*} \mathrm{P}<0.05,{ }^{* *} \mathrm{P}<0.01$ vs. control group. EGFR, endothelial growth factor receptor; MUC5AC, mucin 5AC.

animal models, as the clinical translation of curcumin has been hampered due to its poor bioavailability (34). Further studies should be performed to improve the pharmacological effects of curcumin. 
The present study confirmed that curcumin suppresses MUC5AC production in human bronchial epithelial cells under basal and EGF-stimulated conditions. This inhibition was accompanied by decreased activation of the EGFR/AKT/STAT3 signaling and reduced EGFR expression, which indicated that curcumin may have a dual role in interfering with the EGFR signaling pathway and inhibiting mucin expression in human airway epithelial cells.

\section{Acknowledgements}

Not applicable.

\section{Funding}

This study was supported by the National Natural Science Foundation of China (grant no. 81402988), the Putuo Key Clinical Specialist Construction Programs (grant no. 2014-A-23), the Scientific Foundation of Putuo Hospital (grant no. 2016206A), the Scientific Innovation Foundation of Putuo District (grant no. 17-PT-14) and Department of Respiratory Medicine Development Fund of Putuo District (grant no. 2016PTZK03).

\section{Availability of data and materials}

The analyzed data sets generated during the study are available from the corresponding author on reasonable request.

\section{Authors' contributions}

LT, QC and LS conducted the molecular studies and drafted the manuscript. LZ, JL and ZM participated in the laboratory measurement and data analysis. ZN and XW conceived the study, contributed to the study design and coordination, and participated in drafting the manuscript. All authors read and approved the final manuscript.

\section{Ethical approval and consent to participate}

Not applicable.

\section{Consent for publication}

Not applicable.

\section{Competing interests}

The authors declare that they have no competing interests.

\section{References}

1. Alhassan S, Hattab Y, Bajwa O, Bihler E and Singh AC: Asthma Crit Care Nurs Q 39: 110-123, 2016.

2. DeVries A and Vercelli D: Epigenetic mechanisms in asthma. Ann Am Thorac Soc 13 (Suppl 1): S48-S50, 2016.

3. Evans CM, Kim K, Tuvim MJ and Dickey BF: Mucus hypersecretion in asthma: Causes and effects. Curr Opin Pulm Med 15: 4-11, 2009.

4. Lai HY and Rogers DF: Mucus hypersecretion in asthma: Intracellular signalling pathways as targets for pharmacotherapy. Curr Opin Allergy Clin Immunol 10: 67-76, 2010.
5. Gokce EC, Kahveci R, Gokce A, Sargon MF, Kisa U, Aksoy N, Cemil B and Erdogan B: Curcumin attenuates inflammation, oxidative stress, and ultrastructural damage induced by spinal cord ischemia-reperfusion injury in rats. J Stroke Cerebrovasc Dis 25: 1196-1207, 2016.

6. Bayomi SM, El-Kashef HA, El-Ashmawy MB, Nasr MN, El-Sherbeny MA, Abdel-Aziz NI, El-Sayed MA, Suddek GM, El-Messery SM and Ghaly MA: Synthesis and biological evaluation of new curcumin analogues as antioxidant and antitumor agents: Molecular modeling study. Eur J Med Chem 101: 584-594, 2015.

7. Jeong EH, Vaidya B, Cho SY, Park MA, Kaewintajuk K, Kim SR, Oh MJ, Choi JS, Kwon J and Kim D: Identification of regulators of the early stage of viral hemorrhagic septicemia virus infection during curcumin treatment. Fish Shellfish Immunol 45: 184-193, 2015.

8. Narumoto O, Matsuo Y, Sakaguchi M, Shoji S, Yamashita N, Schubert D, Abe K, Horiguchi K, Nagase T and Yamashita N: Suppressive effects of a pyrazole derivative of curcumin on airway inflammation and remodeling. Exp Mol Pathol 93: 18-25, 2012

9. Heo HJ, Lee SY, Lee MN, Lee HJ, Seok JH and Lee CJ: Genistein and curcumin suppress epidermal growth factor-induced MUC5AC mucin production and gene expression from human airway epithelial cells. Phytother Res 23: 1458-1461, 2009.

10. Yan F, Li W, Zhou H, Wu Y, Ying S, Chen Z and Shen H: Interleukin-13-induced MUC5AC expression is regulated by a PI3K-NFAT3 pathway in mouse tracheal epithelial cells. Biochem Biophys Res Commun 446: 49-53, 2014.

11. Sikder MA, Lee HJ, Mia MZ, Park SH, Ryu J, Kim JH, Min SY, Hong $\mathrm{JH}$, Seok $\mathrm{JH}$ and Lee CJ: Inhibition of TNF- $\alpha$-induced MUC5AC mucin gene expression and production by wogonin through the inactivation of NF- $\kappa \mathrm{B}$ signaling in airway epithelial cells. Phytother Res 28: 62-68, 2014.

12. Kim HJ, Park SH, Park SY, Moon UY, Lee BD, Yoon SH, Lee JG, Baek SJ and Yoon JH: Epigallocatechin-3-gallate inhibits interleukin-1beta-induced MUC5AC gene expression and MUC5AC secretion in normal human nasal epithelial cells. J Nutri Biochem 19: 536-544, 2008.

13. Wang W, Xu X, Zheng M and Wan L: Lipopolysaccharides induces MUC5AC overproduction in human nasal epithelium. Eur Arch Otorhinolaryngol 270: 541-547, 2013.

14. Song S, Byrd JC, Guha S, Liu KF, Koul D and Bresalier RS: Induction of MUC5AC mucin by conjugated bile acids in the esophagus involves the phosphatidylinositol 3-kinase/protein kinase C/activator protein-1 pathway. Cancer 117: 2386-2397, 2011.

15. Nie YC, Wu H, Li PB, Xie LM, Luo YL, Shen JG and Su WW: Naringin attenuates EGF-induced MUC5AC secretion in A549 cells by suppressing the cooperative activities of MAPKs-AP-1 and IKKs-IкB-NF-кB signaling pathways. Eur J Pharmacol 690: 207-213, 2012.

16. Navidshad B, Liang JB and Jahromi MF: Correlation coefficients between different methods of expressing bacterial quantification using real time PCR. Int J Mol Sci 13: 2119-2132, 2012.

17. Livak KJ and Schmittgen TD: Analysis of relative gene expression data using real-time quantitative PCR and the 2(-Delta Delta C(T)) method. Methods 25: 402-408, 2001.

18. Ruchaud-Sparagano MH, Westley BR and May FE: The trefoil protein TFF1 is bound to MUC5AC in human gastric mucosa. Cell Mol Life Sci 61: 1946-1954, 2004.

19. Kanai K, Koarai A, Shishikura Y, Sugiura H, Ichikawa T, Kikuchi T, Akamatsu K,Hirano T, Nakanishi M, Matsunaga K, et al: Cigarette smoke augments MUC5AC production via the TLR3-EGFR pathway in airway epithelial cells. Respir Investig 53: 137-148, 2015.

20. Abdelhamed S, Ogura K, Yokoyama S, Saiki I and Hayakawa Y: AKT-STAT3 pathway as a downstream target of EGFR signaling to regulate PD-L1 expression on NSCLC cells. J Cancer 7: 1579-1586, 2016.

21. Yang J, Li Q, Zhou XD, Kolosov VP and Perelman JM: Naringenin attenuates mucous hypersecretion by modulating reactive oxygen species production and inhibiting NF- $\mathrm{KB}$ activity via EGFR-PI3K-Akt/ERK MAPKinase signaling in human airway epithelial cells. Mol Cell Biochem 351: 29-40, 2011.

22. Rahman I and Chung S: Dietary polyphenols, deacetylases and chromatin remodeling in inflammation. World Rev Nutr Diet 101: 84-94, 2010.

23. Lv S, Dai C, Liu Y, Sun B, Shi R, Han M, Bian R and Wang R: Cell surface protein C23 affects EGF-EGFR induced activation of ERK and PI3K-AKT pathways. J Mol Neurosci 55: 519-524, 2015. 
24. Duan H, Qu L and Shou C: Activation of EGFR-PI3K-AKT signaling is required for Mycoplasma hyorhinis-promoted gastric cancer cell migration. Cancer Cell Int 14: 135, 2014.

25. Yu Q, Chen X, Fang X, Chen Q and Hu C: Caveolin-1 aggravates cigarette smoke extract-induced MUC5AC secretion in human airway epithelial cells. Int J Mol Med 35: 1435-1442, 2015.

26. Zhen G, Park SW, Nguyenvu LT, Rodriguez MW, Barbeau R, Paquet AC and Erle DJ: IL-13 and epidermal growth factor receptor have critical but distinct roles in epithelial cell mucin production. Am J Respirat Cell Mol Biol 36: 244-253, 2007.

27. Le Cras TD, Acciani TH, Mushaben EM, Kramer EL, Pastura PA, Hardie WD, Korfhagen TR, Sivaprasad U, Ericksen M, Gibson AM, et al: Epithelial EGF receptor signaling mediates airway hyperreactivity and remodeling in a mouse model of chronic asthma. Am J Physiol Lung Cell Mol Physiol 300: L414-L421, 2011.

28. Starok M, Preira P, Vayssade M, Haupt K, Salomé L and Rossi C: EGFR inhibition by curcumin in cancer cells: A dual mode of action. Biomacromolecules 16: 1634-1642, 2015.

29. Jiang AP, Zhou DH, Meng XL, Zhang AP, Zhang C, Li XT and Feng Q: Down-regulation of epidermal growth factor receptor by curcumin-induced UBE1L in human bronchial epithelial cells. J Nutr Biochem 25: 241-249, 2014
30. Lee JY, Lee YM, Chang GC, Yu SL, Hsieh WY, Chen JJ, Chen HW and Yang PC: Curcumin induces EGFR degradation in lung adenocarcinoma and modulates p38 activation in intestine: The versatile adjuvant for gefitinib therapy. PLoS One 6: e23756, 2011.

31. Chang JH, Song KJ, Kim HJ, Kim JH, Kim NH and Kim KS: Dietary polyphenols affect MUC5AC expression and ciliary movement in respiratory cells and nasal mucosa. Am J Rhinol Allergy 24: e59-e62, 2010.

32. Song S, Byrd JC, Koo JS and Bresalier RS: Bile acids induce MUC2 overexpression in human colon carcinoma cells. Cancer 103: 1606-1614, 2005.

33. Subhashini, Chauhan PS and Singh R: Ovalbumin-induced allergic inflammation lead to structural alterations in mouse model and protective effects of intranasal curcumin: A comparative study. Allergol Immunopathol (Madr) 44: 246-256, 2016.

34. Lelli D, Sahebkar A, Johnston TP and Pedone C: Curcumin use in pulmonary diseases: State of the art and future perspectives. Pharmacol Res 115:133-148, 2017. 